\title{
The Radiation Sterilization of Ertapenem Sodium in the Solid State
}

\author{
Karolina Kilińska ${ }^{1}$, Judyta Cielecka-Piontek ${ }^{1}$ (D) Robert Skibiński $^{2}{ }^{\mathbb{D}}$, Daria Szymanowska ${ }^{3}$, \\ Andrzej Miklaszewski ${ }^{4}\left(\mathbb{D}\right.$, Kornelia Lewandowska ${ }^{5}$, Waldemar Bednarski ${ }^{5}{ }^{(}$, \\ Mikołaj Mizera ${ }^{1}$ (D), Ewa Tykarska ${ }^{6}$ and Przemysław Zalewski ${ }^{1, *(D)}$ \\ 1 Department of Pharmacognosy, Poznan University of Medical Sciences, Święcickiego 4, \\ 60-781 Poznań, Poland \\ 2 Department of Medicinal Chemistry, Medical University of Lublin, Jaczewskiego 4, 20-090 Lublin, Poland \\ 3 Department of Biotechnology and Food Microbiology, Poznan University of Life Sciences, Wojska Polskiego \\ 48, 60-627 Poznań, Poland \\ 4 Institute of Material Science and Engineering, Poznan University of Technology, Jana Pawła II 24, \\ 60-965 Poznań, Poland \\ 5 Institute of Molecular Physics, Polish Academy of Sciences, Smoluchowskiego 17, 60-179 Poznań, Poland \\ 6 Department of Chemical Technology of Drugs, Poznan University of Medical Sciences, Grunwaldzka 6, \\ 60-780 Poznan, Poland \\ * Correspondence: pzalewski@ump.edu.pl; Tel.: +48-618-546-707
}

Academic Editor: Fernando Albericio

Received: 22 July 2019; Accepted: 11 August 2019; Published: 14 August 2019

\begin{abstract}
For the first time, the influence of ionising radiation on the physicochemical properties of ertapenem in solid state was studied. During our studies, we evaluated the possibility of applying radiosterilization to obtain sterile ertapenem. Spectroscopic (Fourier Transform Infrared (FT-IR)), thermal (differential scanning calorimetry (DSC), chromatography (High-Performance Liquid Chromatography (HPLC) and HPLC-MS), and X-ray powder diffraction (XRPD) studies shown that irradiation of ertapenem with the $25 \mathrm{kGy}$, the dose required to achieve sterility, does not change the physicochemical properties of the studied compound. The antimicrobial activity of ertapenem irradiated with the dose of $25 \mathrm{kGy}$ was only reduced for one species. Based on the received results, we can conclude that radiostelization is a promising alternative method of obtaining sterile ertapenem. In our studies, ertapenem was also exposed to e-beam radiation with a dose of $400 \mathrm{kGy}$. It was determined that two novel degradation products that are structurally differently to degradants formed during hydrolysis and thermolysis.
\end{abstract}

Keywords: ertapenem; radiation sterilization; Q-TOF; microbiological activity; FT-IR; HPLC; EPR; XRPD; Raman

\section{Introduction}

Ertapenem in the form of the sodium salt (ERP) is an analogue of the carbapenem- $\mathrm{a} \beta$-lactam antibiotic. ERP has a broad spectrum of antibacterial activity against many Gram-positive and Gram-negative aerobic and anaerobic microorganisms, however it has restricted activity against Acinetobacter species, Pseudomonas aeruginosa, methicillin-resistant staphylococci, and enterococci-nosocomial pathogens [1,2]. It was licensed for parenteral therapy for once daily use in November 2001 in the USA and six months later in Europe, and since then it has been successfully used in the treatment of community acquired pneumonia and complicated infections of skin and skin structure, urinary tract, abdominal, and pelvic cavity [1,2]. The mechanism of action is based on binding to PBPs (penicillin binding proteins) on the bacterial cell wall, thus inhibiting the synthesis of peptidoglycan, which is an essential component, the lack of which 
leads to the weakening and lysis of the cell wall and, consequently, the entire bacterial cell. ERP has favorable structural features, contains a critical $1 \beta$-methyl substituent, thus exhibiting stability to the renal enzyme - dehydropeptidase-1—and it does not require the addition of DHP-1 inhibitors in the clinical use. Ertapenem is stable against hydrolysis by a variety of $\beta$-lactamases, except metallo- $\beta$-lactamases $[3,4]$. The chemical structure of carbapenems makes them very susceptible to degradation under the condition of high temperature and humidity, which could lead to destruction of their main element, the $\beta$-lactam ring, which is responsible for the antibacterial activity [5,6]. For this reason, it is particularly important to choose the suitable sterilization method for ERP and irradiation seems to be the most advantageous approach. However, the use of this method requires detailed studies and confirmation of the impact of irradiation on the pharmaceutical properties and structure of the drug [7-13].

In this paper, the effect of ionizing radiation on ertapenem sodium in the solid state has been investigated. A standard recommended dose of irradiation (25 kGy) [14] and higher radiation doses (50-400 kGy) have been applied for understanding the process of potential changes in ERP after sterilization.

\section{Results}

Our study on radiostability of ertapenem was divided into two areas. The first was identification of ertapenem before and after irradiation based on analytical and biological methods. The second one aimed at evaluating the structure of the degradation products.

The identity evaluation for ERP was confirmed by means of spectroscopic (Fourier Transform Infrared (FT-IR)), thermal-differential scanning calorimetry (DCS) and X-ray powder diffraction (XRPD) studies.

Figures 1 and 2 show theoretical and experimental IR absorption and Raman scattering spectra of ertapenem, respectively. Theoretical calculation based on the density functional theory (DFT) approach was used in order to conduct particular spectroscopic analysis in regards to all characteristic bands.

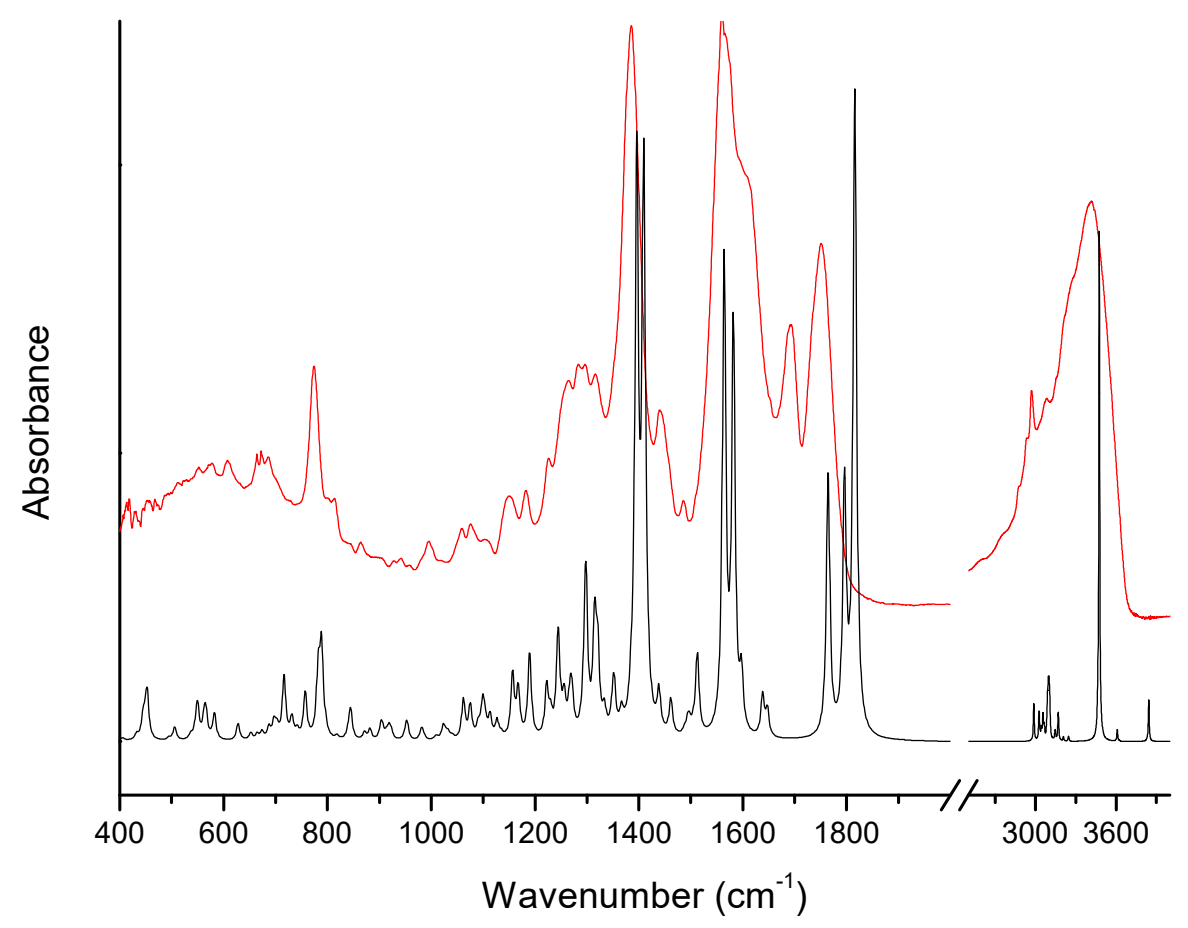

Figure 1. Calculated (black-DFT) and experimental (red) IR absorption spectra of ertapenem at room temperature. 


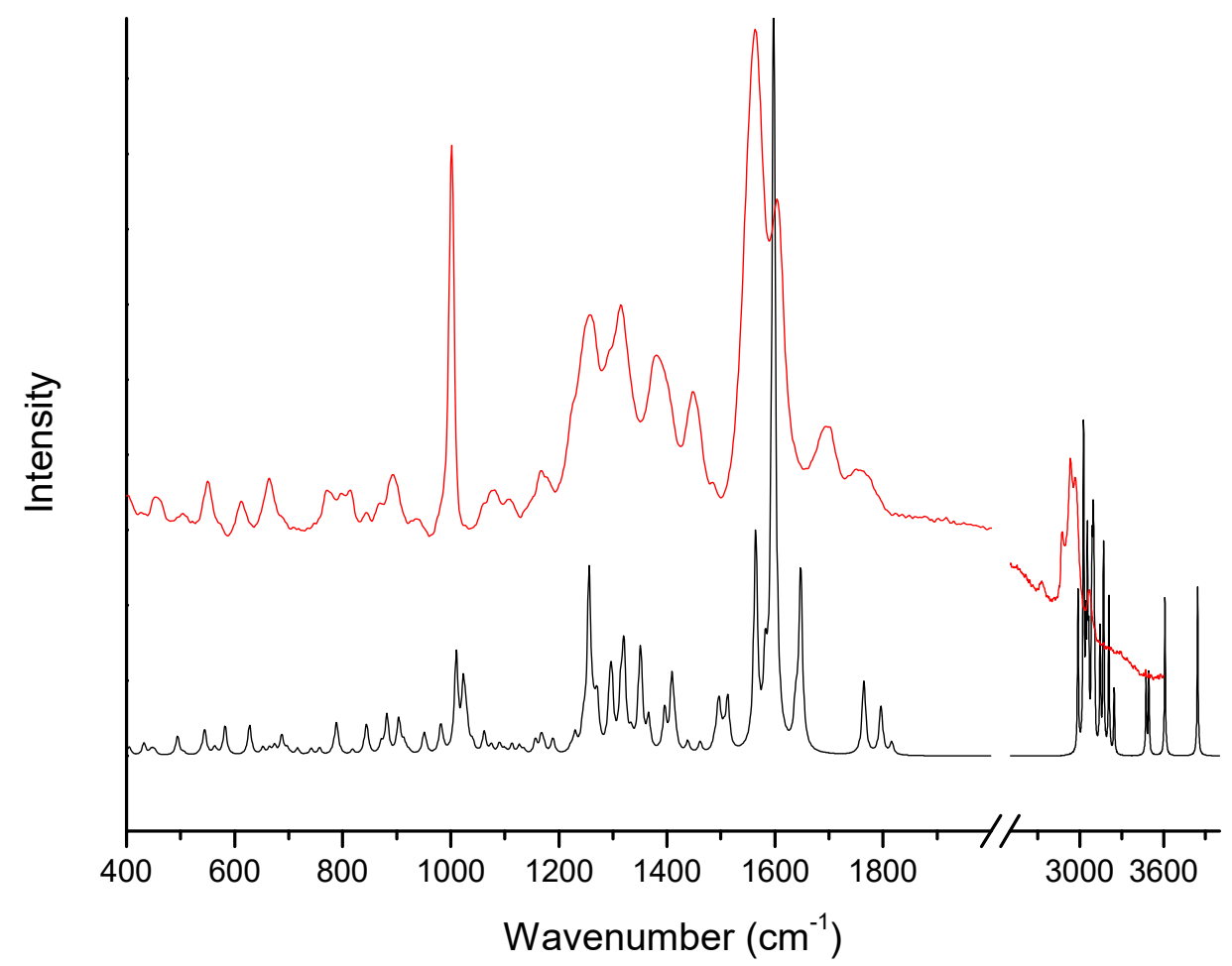

Figure 2. Calculated (black-DFT) and experimental (red) Raman scattering spectra of ertapenem at room temperature.

The bands related to the respective groups/rings of ERP molecule can be distinguished in both the Raman scattering and IR absorption spectra. Accordingly, for the $\beta$-lactam ring, the bands are characteristically located in IR absorption spectrum at $675,992,1075,1100,1151,1180,1291,1385,1750$, and 3263 and $3406 \mathrm{~cm}^{-1}$. The bands related to the vibration of the bonds in the $\beta$-lactam ring are also visible in Raman scattering spectrum and they are observed at 549, 816, 1077, 1100, 1169, 1382, 1601, and $1755 \mathrm{~cm}^{-1}$. The bands that are located in Raman spectrum at 549 and $816 \mathrm{~cm}^{-1}$ are associated with the deformation of the $\beta$-lactam ring. While the bands located at 1075 and $1077 \mathrm{~cm}^{-1}$ in IR absorption and Raman scattering spectra, respectively, are related to the breathing of the $\beta$-lactam ring. The bands at 1100,1151 , and $1169 \mathrm{~cm}^{-1}$ are mainly corresponding to the stretching vibration of the $C-C$ bonds and $\mathrm{C}-\mathrm{O}$ bonds in $\beta$-lactam ring and near the $\beta$-lactam ring in the $\mathrm{COH}$ and $\mathrm{COOH}$ groups. These bands are also additional components related to the wagging vibration of the $\mathrm{C}-\mathrm{H}$ bonds (see Table 1 ).

The bands located at 1385 and $1382 \mathrm{~cm}^{-1}$ in IR and Raman scattering spectra, respectively, are related to the bending vibration of the $\mathrm{C}-\mathrm{O}-\mathrm{H}$ bonds in $\mathrm{COOH}$ group. Whereas, the band that was observed at $1613 \mathrm{~cm}^{-1}$ in IR absorption spectrum is corresponding to the stretching vibration of the $\mathrm{C}=\mathrm{C}$ bond in $\beta$-lactam ring. At $1750,1755 \mathrm{~cm}^{-1}$ are located the bands related to the stretching vibration of the $\mathrm{C}=\mathrm{O}$ bond in $\mathrm{COOH}$ group. Moreover the bands located at $675,992,1180$, and $1291 \mathrm{~cm}^{-1}$ are related to the deformation vibration out of plane of $\mathrm{C}-\mathrm{H}$ bond in $\mathrm{COOH}$ group, stretching vibration of the C-S bond, wagging vibration of the $\mathrm{C}-\mathrm{H}$ bonds, and stretching vibration of the $\mathrm{C}-\mathrm{N}$ bond in the $\beta$-lactam ring. The bands mainly related to the stretching vibration of the $\mathrm{C}-\mathrm{C}$ bonds and rocking, twisting, and stretching vibration of the $\mathrm{C}-\mathrm{H}$ bonds are also visible for the pyrrolidine ring. Additionally, the bands located in Raman scattering spectrum at 940, 1258, 2883, and $2930 \mathrm{~cm}^{-1}$ are associated with the rocking twisting and stretching vibration of the $\mathrm{C}-\mathrm{H}$ bonds. Whereas, the bands at $775,892 \mathrm{~cm}^{-1}$ are related to the out of plane vibration of the $\mathrm{N}-\mathrm{H}$ bond and stretching vibration of the $\mathrm{C}-\mathrm{C}$ bond, respectively. The stretching vibration of the $\mathrm{C}=\mathrm{O}$ bond in COONa group is located in the IR absorption spectrum in the massif between $1565-1690 \mathrm{~cm}^{-1}$ at about $1572 \mathrm{~cm}^{-1}$. In addition, the bands related to the stretching vibration of the $\mathrm{C}-\mathrm{N}$ bond between pyrrolidine and benzene rings and bending vibration of the C-N-H bonds are also observed. They are located at 1057, 1315/1316, and 
$1565 / 1563 \mathrm{~cm}^{-1}$ in IR/Raman spectra. Whereas, the bands at 1228 and 1692/1695 $\mathrm{cm}^{-1}$ (IR/Raman) are corresponding to the stretching vibration of the $\mathrm{C}-\mathrm{C}$ and $\mathrm{C}=\mathrm{O}$ bonds between the pyrrolidine and benzene rings, respectively. Additionally, the band at $1656 \mathrm{~cm}^{-1}$ that was observed in IR absorption spectrum is related to the stretching vibration of the $\mathrm{C}=\mathrm{C}$ bonds in benzene ring. The very wide band with maxima at 3263 and $3406 \mathrm{~cm}^{-1}$ related to the stretching vibration of the $\mathrm{N}-\mathrm{H}$ and O-H bonds is also observed in IR absorption spectrum above $3000 \mathrm{~cm}^{-1}$.

Table 1. Selected characteristic vibrionic features of ertapenem in the form of the sodium salt (ERP); (s-stretching, b-bending, w-wagging, t-twisting, oop-out of plane).

\begin{tabular}{|c|c|c|c|}
\hline IR $\left(\mathrm{cm}^{-1}\right)$ & RAMAN $\left(\mathrm{cm}^{-1}\right)$ & DFT $\left(\mathrm{cm}^{-1}\right)$ & Bands Assignment \\
\hline & 549 & 544 & Def. $\beta$-lactam ring \\
\hline & 613 & 627 & Def. all molecule \\
\hline & 663 & 687 & Def. benzene ring \\
\hline 675 & & 717 & $\mathrm{O}-\mathrm{H}$ oop. in $\mathrm{COOH}$ \\
\hline \multirow[t]{4}{*}{775} & 775 & 788 & $\mathrm{~N}-\mathrm{H}$ oop. in pyrrolidine ring \\
\hline & 816 & 818 & Def. $\beta$-lactam ring \\
\hline & 892 & 881 & $\mathrm{C}-\mathrm{C} \mathrm{s}+\mathrm{C}-\mathrm{H} \mathrm{w}$ in pyrrolidine ring \\
\hline & 940 & 953 & $\mathrm{C}-\mathrm{H} \mathrm{r}$ in pyrrolidine and benzene rings $+\mathrm{C}-\mathrm{C} \mathrm{s}$ in pyrrolidine ring \\
\hline \multirow[t]{2}{*}{992} & & 981 & C-S s \\
\hline & 1001 & 1010 & Breathing benzene ring $+\mathrm{C}-\mathrm{C}$ s in $\mathrm{C}-\mathrm{C} \mathrm{s}+\mathrm{C}-\mathrm{N}$ s in pyrrolidine ring \\
\hline 1057 & & 1062 & C-N s between pyrrolidine and benzene rings + def. pyrrolidine ring \\
\hline 1075 & 1077 & 1075 & Breathing $\beta$-lactam ring \\
\hline 1100 & 1100 & 1110 & $\mathrm{C}-\mathrm{C}$ s near $\beta$-lactam ring $+\mathrm{C}-\mathrm{O}$ s in $\mathrm{COH}+\mathrm{C}-\mathrm{H}$ w near $\beta$-lactam ring \\
\hline \multirow[t]{2}{*}{1151} & & 1156 & $\mathrm{C}-\mathrm{O}$ s in $\mathrm{COH}+\mathrm{C}-\mathrm{C}$ s near $\beta$-lactam ring $+\mathrm{C}-\mathrm{H}$ w near $\beta$-lactam ring \\
\hline & 1169 & 1167 & $\mathrm{C}-\mathrm{O}$ s in $\mathrm{COOH}+\mathrm{C}-\mathrm{H} w$ \\
\hline 1180 & & 1189 & $\mathrm{C}$-H w near $\beta$-lactam and benzene ring \\
\hline 1228 & & 1222 & $\mathrm{C}-\mathrm{C}$ s between pyrrolidine and benzene rings $+\mathrm{C}-\mathrm{H}$ t near pyrrolidine ring \\
\hline 1262 & 1258 & 1268 & $\mathrm{C}-\mathrm{H}$ t near pyrrolidine ring \\
\hline 1291 & & 1315 & $\mathrm{C}-\mathrm{N} \mathrm{s}$ in $\beta$-lactam ring $+\mathrm{C}-\mathrm{H} w$ near $\beta$-lactam ring \\
\hline 1315 & 1316 & 1320 & $\mathrm{C}-\mathrm{N}$ s between pyrrolidine and benzene rings \\
\hline 1385 & 1382 & 1395 & $\mathrm{C}-\mathrm{O}-\mathrm{H} \mathrm{b}$ in $\mathrm{COOH}$ \\
\hline 1441 & 1445 & 1438 & $\mathrm{C}-\mathrm{H} \mathrm{b}$ in benzene ring \\
\hline 1565 & 1563 & 1564 & $\mathrm{C}-\mathrm{N}-\mathrm{H}$ b \\
\hline 1572 & & 1582 & $\mathrm{C}=\mathrm{O} \mathrm{s}$ in $\mathrm{COONa}$ \\
\hline 1613 & & 1597 & $\mathrm{C}=\mathrm{C} \mathrm{s}$ in $\beta$-lactam ring \\
\hline 1656 & & 1647 & $\mathrm{C}=\mathrm{C} \mathrm{s}$ in benzene ring \\
\hline 1692 & 1695 & 1764 & $\mathrm{C}=\mathrm{O}$ s between pyrrolidine and benzene rings $+\mathrm{C}-\mathrm{N}-\mathrm{H} \mathrm{b}$ \\
\hline \multirow[t]{4}{*}{1750} & 1755 & 1816 & $\mathrm{C}=\mathrm{O} \mathrm{s}$ in $\mathrm{COOH}$ and near $\beta$-lactam ring \\
\hline & 2726 & 2987 & $\mathrm{C}-\mathrm{H} \mathrm{s}$ in \\
\hline & 2883 & 3055 & $\mathrm{C}-\mathrm{H} \mathrm{s}$ in pyrrolidine ring \\
\hline & 2930 & 3171 & $\mathrm{C}-\mathrm{H} \mathrm{s}$ in pyrrolidine ring \\
\hline 2976 & & 3208 & $\mathrm{C}-\mathrm{H} \mathrm{s}$ in benzene ring \\
\hline 3263 & & 3474 & $\mathrm{O}-\mathrm{H}$ in $\mathrm{COOH}$ group $+\mathrm{N}-\mathrm{H} \mathrm{s}$ in pyrrolidine ring \\
\hline 3406 & & 3843 & $\mathrm{O}-\mathrm{H} \mathrm{s}+\mathrm{N}-\mathrm{H} \mathrm{s}$ \\
\hline
\end{tabular}

EPR studies indicate that there are no radicals in the non-irradiated material or free radical concentration is below the sensitivity of the spectrometer $(<0.1 \mathrm{ppm})$. EPR spectrum of irradiated ERP (dose $25 \mathrm{kGy}$ ) consists of two different signals, as presented in Figure 3a. The first signal belongs to the free radical that is described by the following anisotropic values of spectroscopic coefficients: $\mathrm{g}_{\mathrm{x}}=$ $2.021( \pm 0.001), g_{y}=2.0048( \pm 0.0005)$, and $g_{z}=1.984( \pm 0.001)$. This signal was simulated in Figure 3c with the assumption of line width $(\Delta \mathrm{B})$ anisotropy: $\Delta \mathrm{B}_{\mathrm{x}}=14 \mathrm{Gs}, \Delta \mathrm{B}_{\mathrm{y}}=9 \mathrm{Gs}, \Delta \mathrm{B}_{\mathrm{x}}=25 \mathrm{Gs}$. The second, much weaker, isotropic signal (Figure $3 \mathrm{a}$ ) is described by the spectroscopic coefficient $\mathrm{g}_{\text {iso }}=2.018$ $( \pm 0.001)$, and it disappears several hundred hours after irradiation.

After irradiation, some of the radicals recombine (Figure 4) and their decay can be described by the following equation:

$$
I(t)=I_{S}+I_{n} e^{\frac{-t}{T}}
$$

where $I(t)$ is the total concentration of free radicals at any time $t$ after irradiation, $I_{S}$ is the concentration of stable free radicals, $I_{n}$ is the concentration of unstable free radicals, and $T$ is the mean lifetime 
of unstable radicals. After approximations of the equation (1) to the experimental points that are presented in Figure 4, the following parameters were obtained $I(t=0 h)=7.32( \pm 0.85) \mathrm{ppm}, I_{S}=4.02$ $( \pm 0.05) \mathrm{ppm}, I_{n}=3.3( \pm 0.8) \mathrm{ppm}$, and $\mathrm{T}=47( \pm 11) \mathrm{h}$. Summarizing, the $25 \mathrm{kGy}$ irradiation dose causes the formation of radical defects in ERT at a very low level, which does not exceed several ppm.

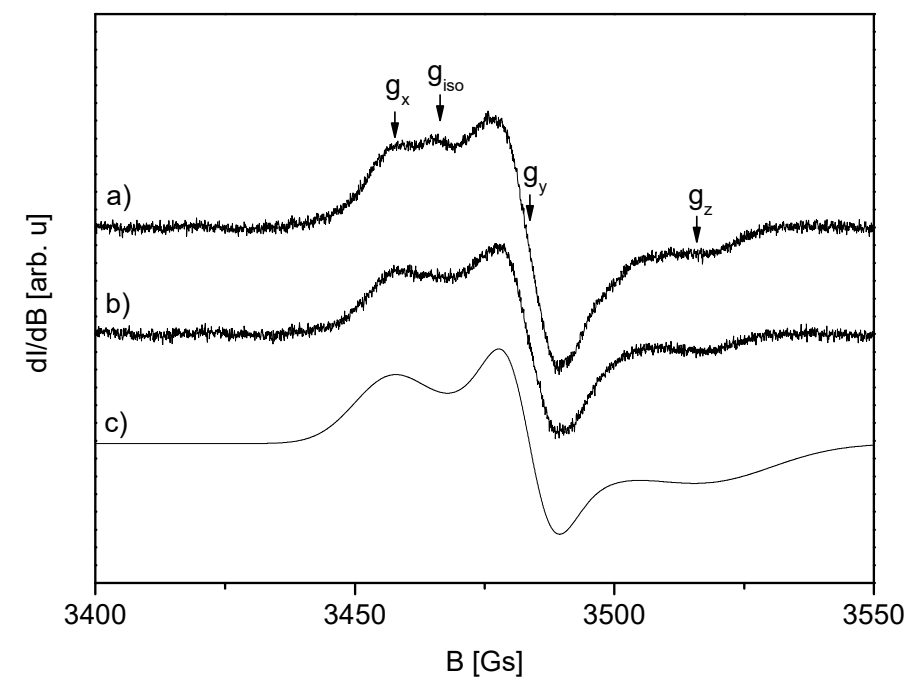

Figure 3. Electron Paramagnetic Resonance (EPR) spectra of the ERP sample recorded at 48.5 (a) and 355.5 (b) hours after irradiation ( $25 \mathrm{kGy}$ ) (c) presents the simulated anisotropic spectrum according to the parameters described in the text.

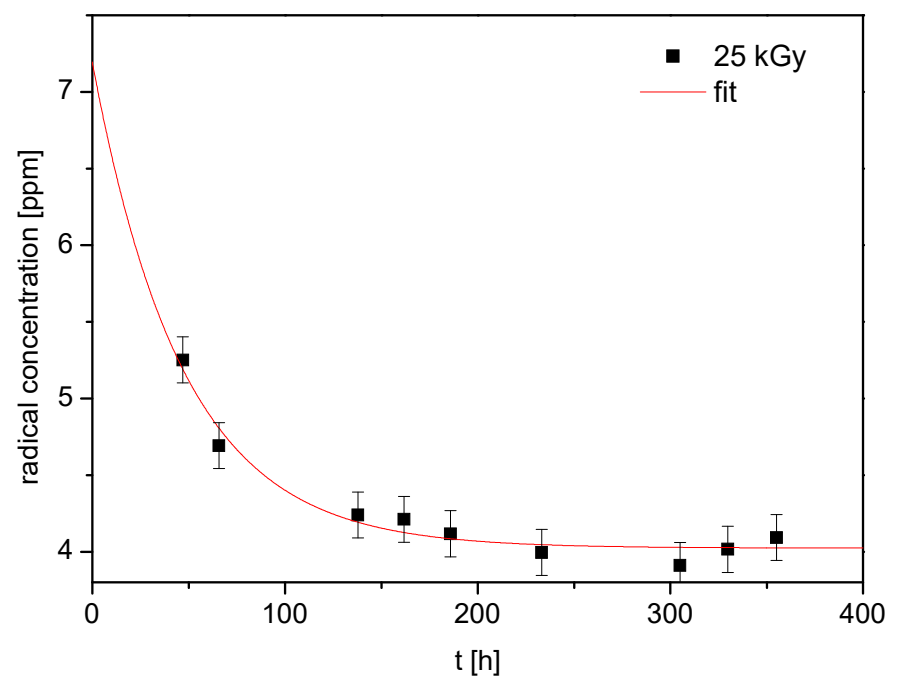

Figure 4. Concentration of free radicals vs. time after sterilisation (irradiation dose $25 \mathrm{kGy}$ ).

For the ERP sample irradiated at the dose of $25 \mathrm{kGy}$, the thermograms only show small changes in the peak position $\left(\Delta \mathrm{T}_{\text {onset }}=4.3{ }^{\circ} \mathrm{C}\right.$ and $\left.\Delta \mathrm{T}_{\text {peak }}=4.69{ }^{\circ} \mathrm{C}\right)$ in the comparison to the reference sample (0 kGy) (Table 2 and Figure 5). The results of melting enthalpies are also similar for both samples $(\Delta \mathrm{H}=52.1843 \mathrm{~J} / \mathrm{g}$ for the non-irradiated sample and $\Delta \mathrm{H}=42.1795 \mathrm{~J} / \mathrm{g}$ for irradiated at $25 \mathrm{kGy}$ dose rate).

However, for the $25 \mathrm{kGy}$ irradiation dose there were no changes in High-Performance Liquid Chromatography-MS/MS (HPLC-MS/MS) or FT-IR, Raman, and XRPD spectra (Figures 6-8).

In our study, a change in the color of samples after exposure to radiation-from white to yellow-was reported. In the next step, we verified the impact of primary packaging material on the ertapenem irradiation. None of the tested packages (PVP and glass containers) allowed for obtaining sterile ERP without color changes of the compound. 
Table 2. Melting enthalpies and characteristic temperatures of ERP from differential scanning calorimetry (DSC) data.

\begin{tabular}{cccc}
\hline (kGy) & $\mathrm{T}_{\text {onset }}\left({ }^{\circ} \mathrm{C}\right)$ & $\mathrm{T}_{\text {endset }}\left({ }^{\circ} \mathrm{C}\right)$ & $\Delta \mathbf{H}(\mathrm{J} / \mathrm{g})$ \\
\hline 0 & 66.5 & 73.9 & 52.2 \\
\hline 25 & 70.8 & 78.7 & 42.2 \\
\hline 400 & 72.9 & 83.5 & 29.5 \\
\hline
\end{tabular}

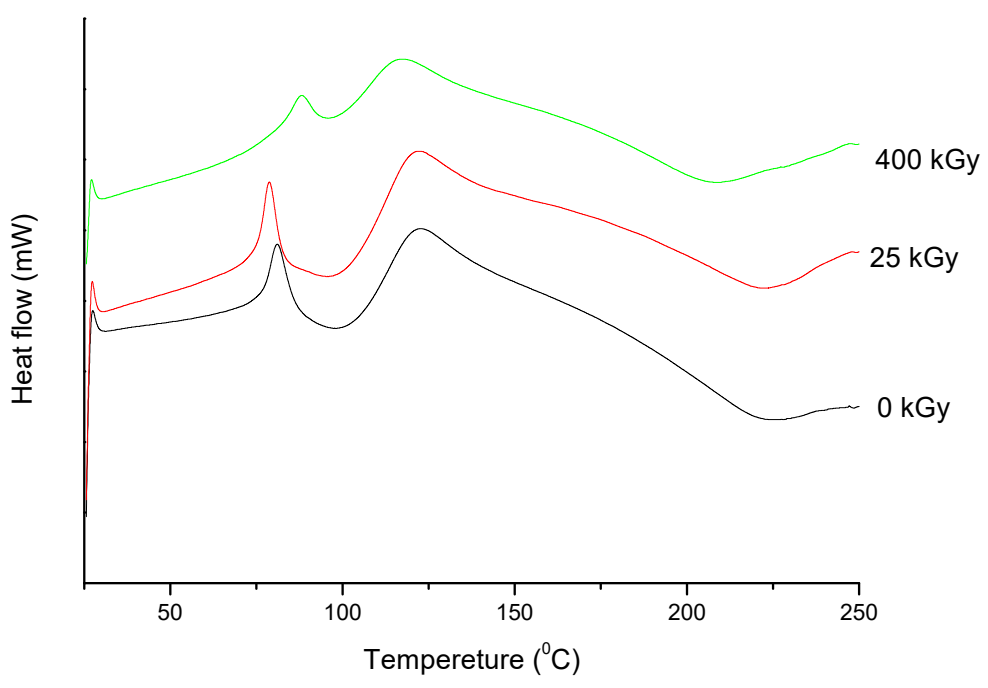

Figure 5. Differential scanning calorimetry (DSC) curves of non-irradiated and irradiated (25 and 400 kGy) ERP.

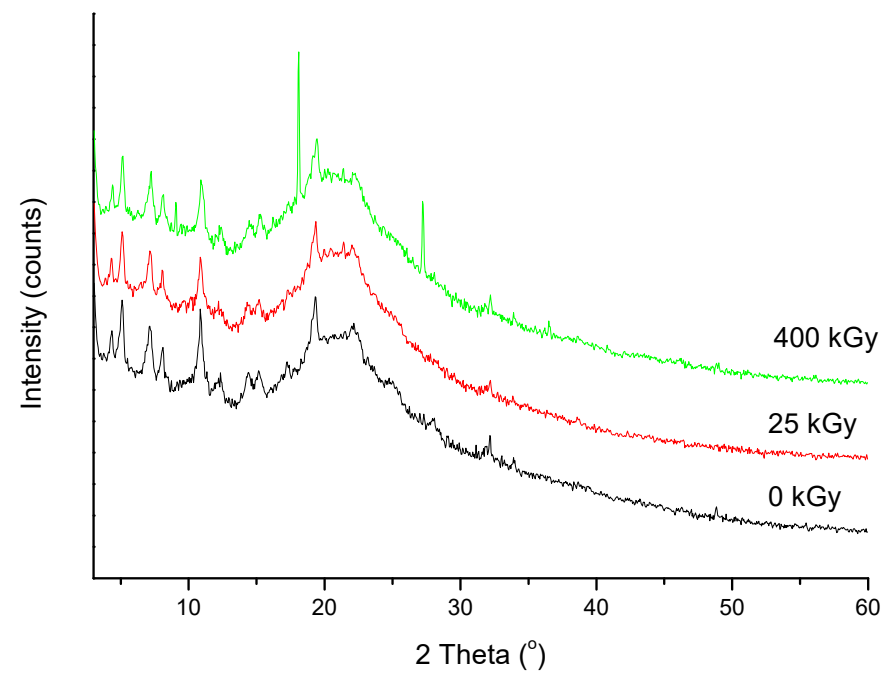

Figure 6. X-ray powder diffraction (XRPD) spectra of non-irradiated and irradiated ERT.

As shown in Figure 6, the XRPD diffractogram of the ERP sample that was irradiated with a dose of $400 \mathrm{kGy}$ differs from the others (0 kGy, $25 \mathrm{kGy}$ ), which indicates the structural changes occurring in the material at higher doses of radiation. Additional diffraction peaks that were observed on the diffractogram of the ERP irradiated with a dose of $400 \mathrm{kGY}$ indicate that there is a mixture of compounds in the sample. 


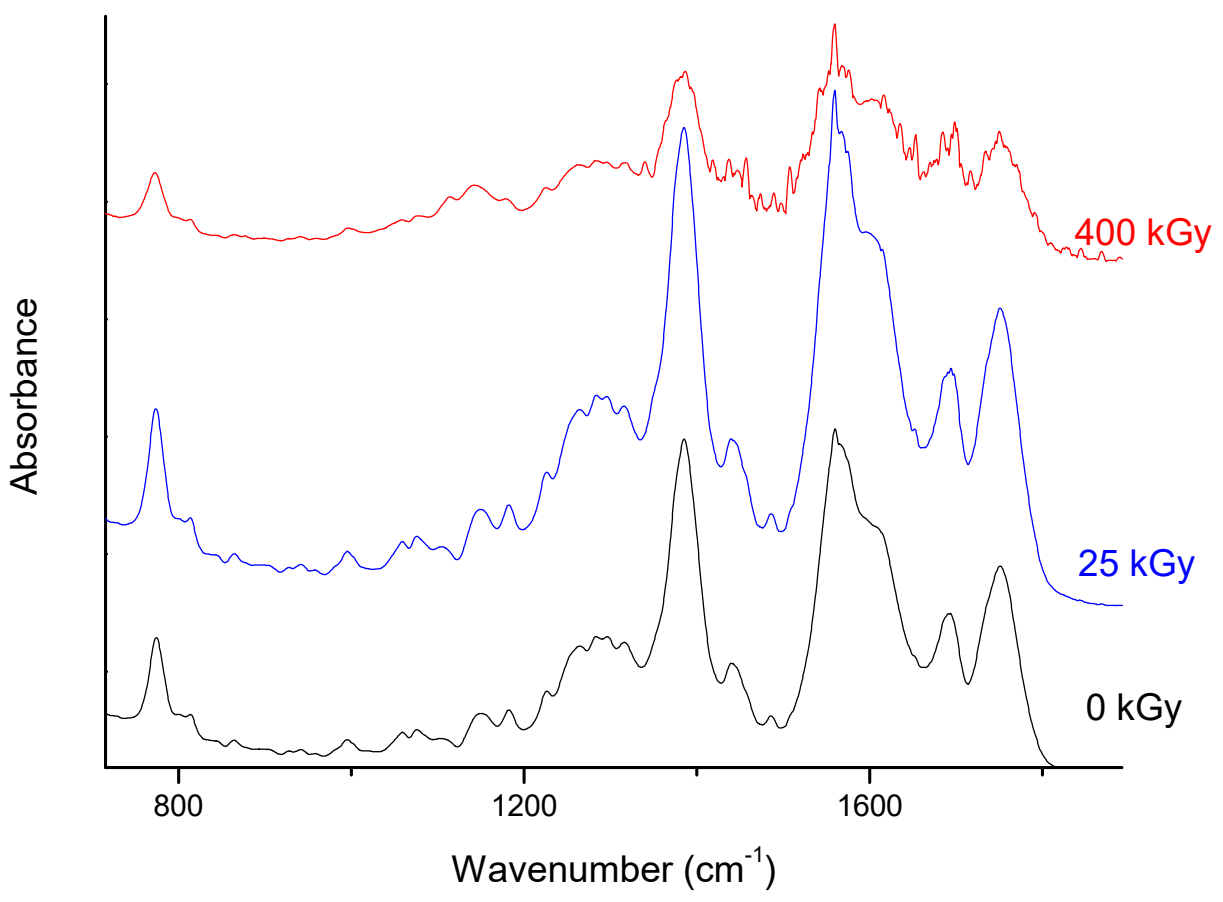

Figure 7. Fourier Transform Infrared (FT-IR) spectra of non-irradiated and irradiated ertapenem.

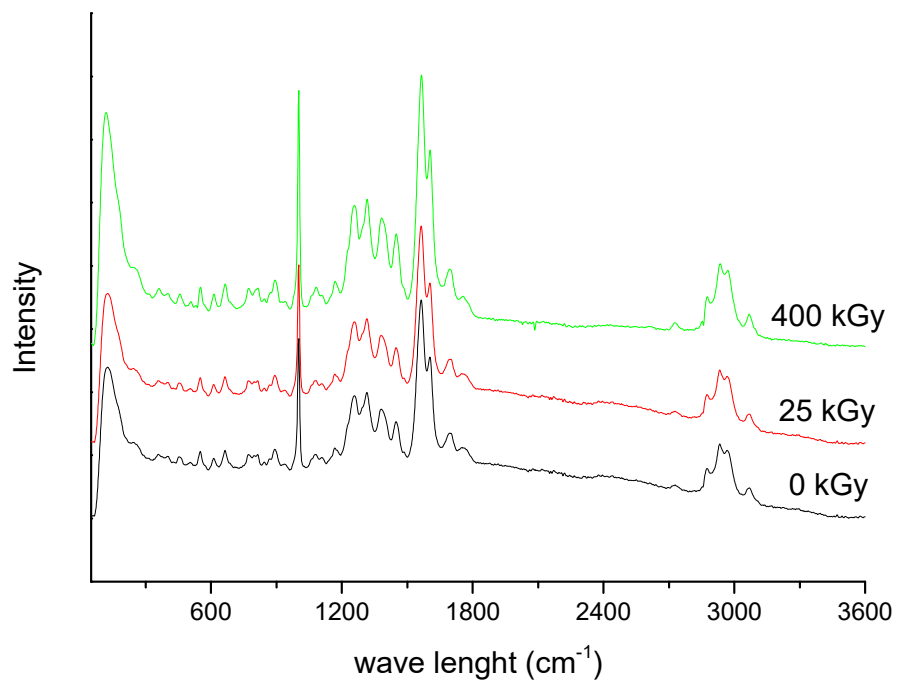

Figure 8. Raman spectra of non-irradiated and irradiated ERP.

At the next stage of the study, the minimum inhibitory concentration (MIC) of ERP against 10 strains of bacteria with pathogenic potential was analyzed. The analysis performed showed the highest MIC value for Pseudomonas mirabilis, Escherichia coli, Salmonella typhimurium, Enterococcus faecalis, Salmonella enteriditis, Pediococcus pentosaceus, Staphylococcus aureus, and Pseudomonas aeruginosa species (250 mg. $\mathrm{L}^{-1}$ ), while the lowest was determined for the Acinetobacter baumanii and Enterobacter aerogenes species $\left(125 \mathrm{mg} \cdot \mathrm{L}^{-1}\right)$. ERP irradiation with the use of $25 \mathrm{kGy}$ radiation only increased the MIC value for Acinetobacter baumanii (Table 3).

Beyond identifying the possible physical changes in the structure of irradiated ERP samples, its chemical stability was tested after exposition to $400 \mathrm{kGy}$. HPLC-diode array detector (HPLC-DAD) analysis of irradiated samples showed a loss of content of $11.5 \%$. The RSD between the three measurements was $1 \%$. The HPLC-MS/MS analysis showed two degradation products of ERP after its irradiation (400 kGy) (Table 4). 
Table 3. MIC values $\left(\mathrm{mg} \cdot \mathrm{L}^{-1}\right)$ of non-irradiated and irradiated ertapenem samples.

\begin{tabular}{lccc}
\hline \multicolumn{1}{c}{ Microorganism } & 0 kGy & 25 kGy & 400 kGy \\
\hline Pseudomonas mirabilis ATCC 12453 & 250 & 250 & - \\
Escherichia coli ATCC 25922 & 250 & 250 & - \\
Salmonella typhimurium ATCC 14028 & 250 & 250 & 250 \\
Acinetobacter baumanii ATCC 19606 & 125 & 250 & 250 \\
Enterococcus faecalis ATTC 29212 & 250 & 250 & - \\
Salmonella enteriditis ATCC 13076 & 250 & 250 & 250 \\
Enterobacter aerogenes ATCC 13048 & 125 & 125 & - \\
Pseudomonas aeruginosa ATCC 27853 & 250 & 250 & - \\
Pediococcus pentosaceus & 250 & 250 & 250 \\
Staphylococcus aureus ATCC 25923 & 250 & 250 & - \\
\hline
\end{tabular}

Table 4. Quadrupole time-of-flight (Q-TOF) accurate mass elemental composition and mass spectrometry/mass spectrometry (MS/MS) fragmentation of the analyzed substances.

\begin{tabular}{|c|c|c|c|c|c|c|c|}
\hline Chemical Structure & $\begin{array}{l}\text { Retention } \\
\text { Time }\end{array}$ & $\begin{array}{l}\text { Measured } \\
\text { Mass }(m / z)\end{array}$ & $\begin{array}{l}\text { Theoretical } \\
\text { Mass }(m / z)\end{array}$ & $\begin{array}{l}\text { Mass } \\
\text { Error } \\
(\mathrm{ppm})\end{array}$ & $\begin{array}{l}\text { Molecular } \\
\text { Formula } \\
{\left[\mathrm{M}+\mathrm{H}^{+}\right]}\end{array}$ & $\begin{array}{l}\text { MS/MS } \\
\text { Fragmentation } \\
\text { Ions }(m / z)\end{array}$ & $\begin{array}{l}\text { MS/MS } \\
\text { Fragment } \\
\text { Formula }\end{array}$ \\
\hline $\begin{array}{l}\text { Ertapenem } \\
\text { coor }\end{array}$ & 7.3 & 476.14955 & 476.14859 & 2.01 & $\mathrm{C}_{22} \mathrm{H}_{26} \mathrm{~N}_{3} \mathrm{O}_{7} \mathrm{~S}$ & $\begin{array}{l}432.15889 \\
346.12227 \\
233.09189 \\
181.07941 \\
114.03702 \\
68.05031\end{array}$ & $\begin{array}{l}\mathrm{C}_{20} \mathrm{H}_{22} \mathrm{~N}_{3} \mathrm{O}_{6} \mathrm{~S} \\
\mathrm{C}_{17} \mathrm{H}_{21} \mathrm{~N}_{3} \mathrm{O}_{3} \mathrm{~S} \\
\mathrm{C}_{12} \mathrm{H}_{13} \mathrm{~N}_{2} \mathrm{O}_{3} \\
\mathrm{C}_{9} \mathrm{H}_{11} \mathrm{NO}_{3} \\
\mathrm{C}_{6} \mathrm{H}_{10} \mathrm{O}_{2} \\
\mathrm{C}_{4} \mathrm{H}_{6} \mathrm{~N}\end{array}$ \\
\hline & 4.2 & 235.10871 & 235.10771 & 4.56 & $\mathrm{C}_{12} \mathrm{H}_{15} \mathrm{~N}_{2} \mathrm{O}_{3}$ & $\begin{array}{l}99.98675 \\
70.06612\end{array}$ & $\begin{array}{l}\mathrm{C}_{5} \mathrm{H}_{12} \mathrm{~N}_{2} \\
\mathrm{C}_{4} \mathrm{H}_{8} \mathrm{~N}\end{array}$ \\
\hline & 5.5 & 267.07880 & 267.07978 & 1.63 & $\mathrm{C}_{12} \mathrm{H}_{15} \mathrm{~N}_{2} \mathrm{O}_{3} \mathrm{~S}$ & $\begin{array}{l}230.96416 \\
182.03794 \\
102.03734 \\
68.04946\end{array}$ & $\begin{array}{l}\mathrm{C}_{12} \mathrm{H}_{11} \mathrm{~N}_{2} \mathrm{O}_{3} \\
\mathrm{C}_{8} \mathrm{H}_{10} \mathrm{~N}_{2} \mathrm{OS} \\
\mathrm{C}_{4} \mathrm{H}_{8} \mathrm{NS} \\
\mathrm{C}_{4} \mathrm{H}_{6} \mathrm{~N}\end{array}$ \\
\hline
\end{tabular}

The molecular ions of ERP and its degradation products (E1 and E2) were very accurately identified (2.01, 4.56, and $1.63 \mathrm{ppm}$, respectively), which allowed for the calculation of the chemical formulas for the analyzed compounds (Table 4). The mass spectrometry/mass spectrometry (MS/MS) fragmentation spectra confirmed the proposed structures of the identified compounds (Table 4).

In addition, the bactericidal properties of ERP irradiated at $400 \mathrm{kGy}$ were completely reduced for six bacterial strains (Table 3 ).

In the absorption spectrum for the ERP sample after irradiation with $400 \mathrm{kGy}$, more bands are observed in Figure 8. It looks that the previously recorded bands for samples without irradiation were splitting. For example, in the range where the band at $1692 \mathrm{~cm}^{-1}$ is observed for ERP, after irradiation there are visible two bands at 1700 and $1684 \mathrm{~cm}^{-1}$. A similar change occurs for the band with a maximum at $1565 \mathrm{~cm}^{-1}$. After irradiation, we can distinguish at least four bands at 1615, 1576, 1559 , and $1541 \mathrm{~cm}^{-1}$. In the range between $1400-1500 \mathrm{~cm}^{-1}$, we can also observe more maxima of bands at 1507, 1488, 1456,1437, and $1419 \mathrm{~cm}^{-1}$. These changes may result from the degradation of the ERP structure after irradiation. However, in the Raman scattering spectra of ERP, no changes can be seen after irradiation (Figure 8). Thus, perhaps the changes recorded for the infrared absorption spectra are the result of the inferior quality of the spectrum, resulting perhaps from the presence of water. 


\section{Discussion}

Previous research concerning the radiostability of $\beta$-lactams antibiotics have confirmed their susceptibility to degradation [7-13]. Test results-both identification methods and stability tests-carried out for solid ERP reflect this statement.

According to the described results, after the irradiation of the sample with a dose of $25 \mathrm{kGy}$, no significant changes in the structure of the compound were identified-referring to spectroscopic (FT-IR, Raman), thermal (DCS), X-ray powder diffraction (XRPD), and mass spectrometry (HPLC-MS/MS) studies. On the other hand, a little decrease of absorption was observed in UV spectra and most likely, it is connected with minor degradation of ERP. This fact was additionally confirmed in EPR studies, where the formation of free radicals was identified after irradiation with $25 \mathrm{kGy}$-the result was at a very low level, which does not exceed several ppm. In addition, stability was assessed by HPLC-DAD analysis [15], which showed a slight decrease in the content.

The use of a high irradiation dose (400 kGy) on ERP strongly intensified the effect of ERP degradation and allowed for the identification of degradation products by HPLC-MS/MS analysis (Table 4). The radiolysis products were therefore formed as a decomposition of the bond connecting substituent of $\beta$-lactam ring. This change decreases the bactericidal properties of ERP and it has been confirmed in the carried out tests.

The literature data confirm that discoloration or yellowing is the most common problem that is encountered after radiosterilisation of solid drugs [11]. What is particularly important, after dissolving the ERP irradiated samples in water for injections, we get clear and colorless solutions. Therefore, the authors suggest that the change in the color of ERP in the solid state after exposure to irradiation may be related to the presence of radiolyzed water that is trapped in the crystal structure of ERP.

The microbiological study demonstrated the stability of ERP biological activity after irradiation with a dose of $25 \mathrm{kGy}$. An increase in a MIC value was identified for only one species-Acinetobacter baumanii-but the increase was only to the standard MIC level that is presented by other species. Only the application of $400 \mathrm{kGy}$ radiation dose shows a significant reduction and even the disappearance of bactericidal properties of ERP, which corresponds to earlier results of studies showing the decomposition of the compound ( $\beta$-lactam ring opening) and formation of degradation products.

The conducted studies confirm the thesis put forward-ERP in solid state shows stability after irradiation with the dose of 25kGy and it maintains its pharmacological properties. The application of a very high radiation dose (400kGy) allowed for understanding physicochemical changes taking place in the molecule, identifying the degradation products, and linking them to changes in the bactericidal properties of ERP. It also confirms the need to conduct research for each molecule separately due to its individual response to radiation in comparison with compounds from the same group of drugs [9-11].

\section{Materials and Methods}

\subsection{Standards and Reagents}

Ertapenem sodium (ERT) was obtained from Glentham Life Sciences (Wiltshire, United Kingdom); it is a white to off-white, weakly crystalline, sterile salt with purity $>90.0 \%$. ERP is soluble in water and $0.9 \%$ sodium chloride solution. All other chemicals and solvents were obtained from Merck KGaA (Darmstadt, Germany) and they were of analytical grade. High quality pure water was prepared while using the Millipore purification system (Millipore, Molsheim, France, model Exil SA 67120).

\subsection{Irradiation}

The samples of ERP were weighted into colorless glass vials in an amount of $5 \mathrm{mg}$ and closed with plastic stoppers. All of the vials were exposed to $\beta$-irradiation in a linear electron accelerator LAE 13/9 (9.96 MeV electron beam and $6.2 \mu \mathrm{A}$ current intensity) until doses of 25 and $400 \mathrm{kGy}$ were absorbed. 


\subsection{Fourier Transform Infrared (FT-IR) Spectroscopy}

The spectra were determined while using Fourier Transform Infrared (FT-IR) spectrometer, IR Affinity-1 Shimadzu. The samples were prepared by mixing ERP with potassium bromide in proportions of $1 \mathrm{mg}$ of sample to $300 \mathrm{mg} \mathrm{KBr}$. Pellets were formed under pressure of $15 \mathrm{ton} / \mathrm{cm}^{2} \mathrm{with}$ a barrel of $13 \mathrm{~mm}$ in diameter. Absorption spectra were recorded with resolution of $2 \mathrm{~cm}^{-1}$ within a wavenumber range from 4000 to $400 \mathrm{~cm}^{-1}$ (30 scans per spectrum).

\subsection{Electron Paramagnetic Resonance (EPR) Spectroscopy}

The detection of the level of free radicals was carried out while using a Bruker ELEXSYS 500 spectrometer (Bruker, Billerica, MA, USA). The irradiated and non-irradiated powdered samples of ertapenem were tested in quartz capillaries at temperature $24{ }^{\circ} \mathrm{C}$ (X-band, $\left.9.7 \mathrm{GHz}\right)$. EPR spectra were recorded as a first derivative of the absorption signal. The spectra were accumulated 10 times due to the very small EPR signal, and the free radicals number was subsequently calculated using the method described elsewhere [16].

\subsection{High-Performance Liquid Chromatography (HPLC-DAD) Analysis}

The kinetic studies of ERP samples and separation of degradation products were conducted by the use of the Dionex Ultimate 3000 analytical system that consisted of a quaternary pump, an autosampler, a column oven, and a diode array detector (Dionex, Sunnyvale, CA, USA). The LiChrospher RP18, $5 \mu \mathrm{m}$ particle size, $250 \mathrm{~mm} \times 4 \mathrm{~mm}$ was used as a stationary phase and the composition of $25 \mathrm{mM}$ phosphate buffer—methanol $(85: 15 \mathrm{v} / \mathrm{v})$ —mobile phase. The flow rate was $1.2 \mathrm{~mL} \cdot \mathrm{min}^{-1}$. The $5.0 \mathrm{mg}$ of each ERP samples were dissolved in $25.0 \mathrm{~mL}$ of water and the injection volume for HPLC analysis was $10 \mu \mathrm{L}$. Separation was performed at temperature $30^{\circ} \mathrm{C}$ and the wavelength of the diode array detector (DAD) was set at $294 \mathrm{~nm}$ [15].

\subsection{HPLC-MS/MS Analysis}

The analysis was conducted with use of an Agilent Accurate-Mass Q-TOF LC/MS G6520B system with a DESI ion source and an Infinity 1290 ultra-high-pressure liquid chromatography system consisting of a G4220A binary pump, a G1330B FC/ALS thermostat, a G4226A autosampler, a G4212A DAD, and a G1316C TCC module (Agilent Technologies, Santa Clara, CA, USA). The control of the system, data acquisition, and qualitative analysis were conducted with the use of the MassHunter workstation software B.04.00. Separations were performed on Hibar RP-18e (2 $\mu \mathrm{m}$ particle size, $50 \mathrm{~mm}$ $\times 2.1 \mathrm{~mm}$ (Merck). The initial mobile phase composition was methanol $-0.05 \%$ acetic acid (5:95) during $2 \mathrm{~min}$. Then gradient elution was used, starting from mobile phase composition ratio (10:90) after $2 \mathrm{~min}$. to $50: 50$ within $10 \mathrm{~min}$. and the flow rate of the mobile phase was $0.3 \mathrm{~mL} \cdot \mathrm{min}^{-1}$. The Q-TOF detector was tuned in the positive $(4 \mathrm{GHz})$ and the main parameters were optimized, as follows: drying gas $10 \mathrm{~L} / \mathrm{min}$., nebulizer pressure $40 \mathrm{psig}$, gas temp. $300^{\circ} \mathrm{C}$, capillary voltage $3500 \mathrm{~V}$, skimmer voltage $65 \mathrm{~V}$, fragmentor voltage $200 \mathrm{~V}$, and octopole 1 radio frequency voltage $250 \mathrm{~V}$. The data were acquired in the auto MS/MS mode with the mass range 50-950 m/z and the acquisition rate $1.2 \mathrm{spectra} / \mathrm{s}$ (for MS and MS/MS data). The collision energy was calculated from the formula $2 \mathrm{~V}$ (slope) ${ }^{*}(m / z) / 100+6 \mathrm{~V}$ (offset) and maximum two precursors per cycle were selected with an active exclusion mode after 1 spectrum for $0.2 \mathrm{~min}$. The reference mass correction was used and values 121.0508 and $922.0097 \mathrm{~m} / \mathrm{z}$ were selected as lock masses to ensure the accuracy of measurements.

\subsection{X-ray Powder Diffraction (XRPD)}

An X-ray powder diffraction (XRPD) pattern was obtained by means of a PANalitycal Empyrean system with $\mathrm{CuK} \alpha_{1}$ radiation $(1.54056 \AA$ ) at a voltage of $45 \mathrm{kV}$ and a current of $40 \mathrm{~mA}$. The ERP sample was scanned from $3^{\circ}$ to $50^{\circ} 2 \theta$ while using a step size of $0.017^{\circ}$ and the scanning rate $15 \mathrm{~s} / \mathrm{step}$ with the sample spinning. 


\subsection{Microbiological Study}

The MIC (Minimal Inhibitory Concentration) values have been determined for each reference strains from the American Type Culture Collection and clinical isolates to verify the antimicrobial activity of ERP. MICs was assayed while using the serial dilutions method on the Mueller-Hinton liquid medium (Merck, Germany), which follows the standards of the Clinical and Laboratory Standards Institute (CLSI) [17]. In tests, microbial culture with a standardized optical density was used. The experiments for ERP samples were run in triplicate.

\section{Conclusions}

The results of the performed studies allow for concluding that ERP in the solid state is resistant to ionizing radiation in a standard sterilization dose of $25 \mathrm{kGy}$, and this method can safely be used for sterilization and decontamination of this compound. Irradiation with higher dose (400 kGy) leads to the following effects: loss in content of active substance by about $11.5 \%$, radiolytic degradation of ERP with 2 product, lack of microbiological activity for six strains.

Author Contributions: Conceptualization, J.C.-P., P.Z. and K.K.; methodology, J.C.-P., P.Z. and K.K.; formal analysis, P.Z., K.K., R.S., D.S., M.M., A.M., E.T., K.L., W.B.; writing-review and editing, K.K.; J.C.-P., P.Z.; supervision, P.Z.; J.C.-P. project administration, P.Z.; funding acquisition, J.C.-P., M.M., P.Z.

Funding: This research was funded by National Science Centre, Poland, grant number 2017/01/X/NZ7/00141.

Conflicts of Interest: The authors declare no conflict of interest.

\section{References}

1. Zhanel, G.G.; Johanson, C.; Embil, J.M.; Noreddin, A.; Gin, A.; Vercaigne, L.; Hoban, D.J. Ertapenem: Review of a new carbapenem. Expert Rev. Anti-Infect. Ther. 2005, 3, 23-39. [CrossRef] [PubMed]

2. Behera, B.; Mathur, P.; Das, A.; Kapil, A. Ertapenem susceptibility of extended spectrum beta-lactamase-producing Enterobacteriaceae at a tertiary care centre in India. Singap. Med. J. 2009, 50, 628-632.

3. Nix, D.E.; Majumdar, A.K.; DiNubile, M.J. Pharmacokinetics and pharmacodynamics of ertapenem: An overview for clinicians. J. Antimicrob. Chemother. 2004, 53, 23-28. [CrossRef] [PubMed]

4. Odenholt, I. Ertapenem: A new carbapenem. Expert Opin. Investig. Drugs 2001, 10, 1157-1166. [CrossRef] [PubMed]

5. Zajac, M.; Cielecka-Piontek, J.; Jelińska, A. Stability of ertapenem in aqueous solutions. J. Pharm. Biomed. Anal. 2007, 43, 445-449. [CrossRef] [PubMed]

6. Cielecka-Piontek, J.; Zając, M.; Jelińska, A. A comparison of the stability of ertapenem and meropenem in pharmaceutical preparations in solid state. J. Pharm. Biomed. Anal. 2008, 46, 52-57. [CrossRef] [PubMed]

7. Garbacki, P.; Zalewski, P.; Skibiński, R.; Kozak, M.; Ratajczak, M.; Lewandowska, K.; Bednarski, W.; Podborska, A.; Mizera, M.; Jelińska, A.; et al. Radiostability of cefoselis sulfate in the solid state. X-ray Spectrom. 2015, 44, 344-350. [CrossRef]

8. Zalewski, P.; Skibiński, R.; Szymanowska-Powałowska, D.; Piotrowska, H.; Kozak, M.; Pietralik, Z.; Bednarski, W.; Cielecka-Piontek, J. The radiolytic studies of cefpirome sulfate in the solid state. J. Pharm. Biomed. Anal. 2016, 118, 410-416. [CrossRef]

9. Zalewski, P.; Skibiński, R.; Szymanowska-Powałowska, D.; Piotrowska, H.; Bednarski, W.; Cielecka-Piontek, J. Radiolytic studies of cefozopran hydrochloride in the solid state. Electron. J. Biotechnol. 2017, 25, 28-32. [CrossRef]

10. Zalewski, P.; Szymanowska-Powałowska, D.; Garbacki, P.; Paczkowska, M.; Talaczyńska, A.; Cielecka-Piontek, J. The radiolytic studies of ceftriaxone in the solid state. Acta Pol. Pharm. 2015, 72, 1253-1258.

11. Kilińska, K.; Cielecka-Piontek, J.; Skibiński, R.; Szymanowska, D.; Miklaszewski, A.; Bednarski, W.; Tykarska, E.; Stasiłowicz, A.; Zalewski, P. The Radiostability of Meropenem Trihydrate in Solid State. Molecules 2018, 23, 2738. [CrossRef] 
12. Kilińska, K.; Cielecka-Piontek, J.; Skibiński, R.; Szymanowska, D.; Miklaszewski, A.; Bednarski, W.; Zalewski, P. The radiolytic studies of doripenem monohydrate in the solid state. Acta Pol. Pharm. 2018, 75, 1127-1133.

13. Kilińska, K.; Cielecka-Piontek, J.; Skibiński, R.; Szymanowska, D.; Miklaszewski, A.; Bednarski, W.; Zalewski, P. The radiation sterilization of imipenem and cilastatin in the solid state. Acta Pol. Pharm. 2019, $76,431-438$.

14. EN ISO 11137, (2006). Available online: https://www.iso.org/standard/33952.html (accessed on 13 August 2019).

15. Zajac, M.; Cielecka-Piontek, J.; Jelińska, A. Development and validation of UV spectrophotometric and RP-HPLC methods for determination of ertapenem during stability studies. Chem. Anal. 2006, 51, 761-770.

16. Mai, V.C.; Bednarski, W.; Borowiak-Sobkowiak, B.; Wilkaniec, B.; Samardakiewicz, S.; Morkunas, I. Oxidative stress in pea seedling leaves in response to Acyrthosiphon pisum infestation. Phytochemistry 2013, 93, 49-62. [CrossRef]

17. CLSI. M07-A9: Methods for Dilution Antimicrobial Susceptibility Tests for Bacteria That Grow Aerobically; Approved Standard-Ninth Edition; CLSI: Wayne, PA, USA, 2012.

Sample Availability: Not available. 